\title{
Antibiogram of nosocomial urinary tract infections in Felege Hiwot referral hospital, Ethiopia
}

\author{
Melaku S ${ }^{1}$, Kibret $\mathrm{M}^{2}$ Abera B, ${ }^{3}$ Gebre-Sellassie $\mathrm{S}^{4}$
}

1. Bahir Regional Health Research Laboratory Center, P.O. Box 641, Bahir Dar, Ethiopia

2. Department of Biology, Bahir Dar University, Science College, P.O. Box 79, Bahir Dar, Ethiopia

3. Department of Microbiology, Parasitology and Immunology, College of Medicine and Health Sciences, Bahir Dar University, Bahir Dar, Ethiopia

4. Department of Microbiology, Parasitology and Immunology, Faculty of Medicine, Addis Ababa University, Addis Ababa, Ethiopia

\begin{abstract}
Background: Nosocomial infections increase the cost of medical care, extend hospital stay and reflect on the morbidity and mortality of the admitted patients. Urinary tract infections (UTIs) are one of the most common nosocomial infections in humans.

Objectives: To determine the prevalence and antibiogram of nosocomial UITs from a referral hospital.

Methods: A cross-sectional study was conducted on 1254 patients from April to August 2010. Antimicrobial susceptibility tests were done using disc diffusion technique as per the standard of Kirby-Bauer method.

Results: Of the 1254 patients, 118 (9.4\%) developed nosocomial UTIs. Seventy three (61.9\%) and 44 (37.1\%) of the bacterial isolates were gram negative and gram positive, respectively. One patient had a mixed infection. E. coli, S.aureus and K. pneumonia were the most predominant isolates. Gender, catheterization and pre-operative antimicrobial prophylaxis and underlying diseases were significantly associated with the occurrence of nosocomial UTIs $(\mathrm{p}=0.001)$. Most bacterial isolates showed high resistance rates $(>80 \%)$ to ampicillin, amoxicillin/clavulanic acid, chloramphenicol and cloxacillin.

Conclusion: Catheterization and preoperative antibiotic prophylaxis were found to be the risk factors for nosocomial infection. Effective infection prevention measures should be in place to reduce the prevalence of nosocomial UTIs.

Key words: Antimicrobial resistance, urinary tract infection, bacteria, nosocomial

African Health Sciences 2012; 12(2): 134- 139 http://dx.doi.org/10.4314/ahs.v12i2.9
\end{abstract}

\section{Introduction}

The quality of health care provision at any level of health facilities is affected by many factors among which nosocomial infection stands in forefront. Nosocomial infections are defined as infections that are identified between 48 and 72 hours after a patient is admitted to a hospital ${ }^{1}$. With the increased use of invasive procedures, at least $8 \%$ of patients acquire nosocomial infections ${ }^{1,2}$. Nosocomial infections increase the cost of medical care, extend the duration of hospital stay, and reflect on the morbidity and mortality of the admitted patients ${ }^{3}$. The health care

\author{
*Correspondence author: \\ Mulugeta Kibret \\ Department of Biology \\ Science College, Bahir Dar University \\ P.O. Box 79 \\ Bahir Dar, Ethiopia \\ Tel: 251-918-780300 \\ E-mail: mulugetanig@gmail.com
}

providers are also at risk of acquiring nosocomial infections and add the functional disability to the health care system ${ }^{4}$.

Urinary tract infections (UTIs) are one of the most common nosocomial infections in humans ${ }^{5}$. Worldwide, approximately 150 million people are diagnosed with urinary tract infections resulting in $\$ 6$ billion health care expenditures ${ }^{6}$. These UTIs are the most common bacterial infections encountered by clinicians in developing countries ${ }^{7}$. Most urinary tract infections are caused by gram-negative bacteria like Escherichia coli, Klebsiella spp., Proteus mirabilis, Pseudomonas aeruginosa, Acinetobacter spp., and Serratia spp, and gram-positive bacteria such as Enterococcus

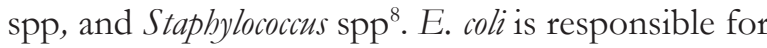
most UTIs ${ }^{9}$. Drug resistance among bacteria causing UTI has increased since introduction to UTI chemotherapy ${ }^{10}$. Use of antimicrobial prophylaxis may lead to unnecessary prolonged antimicrobial dosing which can contribute to development of resistance due to selection pressure.

African Health Sciences Vol 12 No 2 June 2012 
The UTIs from catheterized and hospitalized patients are known to include strains which are resistant to antimicrobials ${ }^{10}$. The etiological agents and their susceptibility patterns of UTI vary in regions and geographical locations. Besides, the etiology and drug resistance change through time ${ }^{11}$. Knowledge of the local bacterial etiology and susceptibility patterns is required to trace any change that might have occurred in time so that updated recommendation for optimal empirical therapy of UTI can be made ${ }^{12}$. Routine antimicrobial sensitivity tests cannot be done in the hospitals of many developing countries. Therefore, empirical therapy of UTIs is based on survey of antimicrobial susceptibility test. The aim of the present study was therefore to investigate prevalence of nosocomial bacterial UTI, assess risk factors and determine the antibiogram of bacterial isolates from a Felege Hiwot referral hospital.

\section{Methods \\ Patients}

A prospective cross-sectional study was conducted to determine the prevalence and antimicrobial susceptibility of urinary tract infections at Felege Hiwot referral hospital from April to August, 2010. Patients aged 18 years and above who were admitted to surgical, gynecology and obstetrics wards were subjected to diagnosis for nosocomial UTIs. Patients with at least one of the following signs or symptoms with (no other recognized cause): fever $\left(>38^{\circ} \mathrm{C}\right.$ ), urgency, frequency, dysuria, or suprapubic tenderness and patient who had positive urine culture i.e. $\geq$, $10^{5} \mathrm{cfu} / \mathrm{ml}$ of urine with no more than two species of microorganisms were considered in the study.

A total of 1254 adult patients consecutively admitted to surgical, gynecology and obstetrics wards were monitored by the surgeons and gynecologists in the respective wards developing UTI during their hospital stay during the study period. Age and sex of the patients, and risk factor of the patients such as history of cathetherization, use of prophylaxis and underlying diseases were assessed by practicing nurses.

\section{Data and specimen collection}

Data on socio-demographic characteristics of patients, associated risk factors, and clinical status on admission of each patient were collected with a questionnaire. Patients were followed during their admission/postoperative period for the development of UTI, which is noted until the day of their discharge. Clinically suggestive nosocomial infections were identified based on CDC criteria ${ }^{13}$.

Midstream urine samples were collected aseptically before and after catheterization using a sterilized container for bacteriological examination. The samples were directly inoculated on blood agar, Chromo agar orientation (biomerieux, France) and Cystine-Lactose-Electrolyte Deficient media (Oxoid). Significant bacteriuria was defined as urine culture which grewe $\geq 10^{5}$ colony forming unit $(\mathrm{CFU}) / \mathrm{ml}^{14}$. Cultures were incubated in aerobic atmosphere at $37^{\circ} \mathrm{C}$ for $24-48$ hours. Positive cultures were identified based on their colony characteristics on their respective media and followed by the pattern of biochemical profiles. All gram negative bacteria were identified using API 20E strip (Biomerieux, France). Reference strains S. aureus ATCC 25923, E.coli ATCC 25922, and P. aeruginosa ATCC 27853(BBL) were used as controls.

\section{Antimicrobial susceptibility testing}

Antimicrobial susceptibility tests were done on Mueller-Hinton agar (Oxoid, England), using KirbyBauer disk diffusion method ${ }^{15}$. The antimicrobial agents tested were: ampicillin $(10 \mu \mathrm{g})$, sulphamethoxazole $(25 \mu \mathrm{g})$, amoxycillin $(30 \mu \mathrm{g})$,

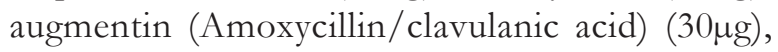
ceftriaxone $(30 \mu \mathrm{g})$, ciprofloxacin $(5 \mu \mathrm{g})$, chloramphenicol (30 $\mu \mathrm{g})$, cloxacillin $(1 \mu \mathrm{g})$, tetracycline $(30 \mu \mathrm{g})$, gentamicin $(10 \mu \mathrm{g})$, and norfloxacillin $(10 \mu \mathrm{g})$.

Morphologically identical 4-6 bacterial colonies from overnight culture were suspended in $5 \mathrm{ml}$ nutrient broth and incubated for 4 hours at $37^{\circ} \mathrm{C}$. Turbidity of the broth culture was equilibrated to match 0.5 McFarland standards. Using sterile swab, the suspension was inoculated onto Mueller Hinton agar and antimicrobial discs were added within 5 minutes of inoculation. After 18-24 hours of incubation, the diameter of growth inhibition around the discs were measured and interpreted as sensitive, intermediate or resistant according to Clinical and Laboratory Standards Institute, formerly known as National Committee for Clinical Laboratory Standards ${ }^{16}$. Reference Strains such as $S$. aureus ATCC 25923, E. coli ATCC 25922, and P. aeruginosa ATCC 27853 (BBL) were used as quality controls for antimicrobial susceptibility tests.

\section{Data analysis}

Data were analyzed using SPSS- Version-15.2 to assess differences between variables. Prevalence was calculated for the sum of the numbers of positive 
cases of examined patients. Chi-square test was done to check the presence of associations. Bivariant logistic regression model analysis was applied to assess the risk factors. P-values $<0.05$ were considered statistically significant.

\section{Ethical Consideration}

Ethical approval was secured from the Institutional Review Board (IRB) of the medical faculty of Addis Ababa University. A written consent from the medical director and manager of the hospital was obtained for conducting the study.

\section{Results}

Among the 1254 observed patients, 633 (50.5\%) were females and $621(49.5 \%)$ were males. The age of the patients ranged from 18 to 87 years, with mean age of $33.6(\mathrm{SD}=14.5)$ years. The prevalence of confirmed nosocomial urinary tract infections was $9.4 \%$. Among these, 80 (6.4\%) were females and $38(3.0 \%)$ were males (table 1$)$.

Table 1: Age and sex distribution of patients with suspected urinary tract infection at Felege Hiwot Referral Hospital (April to August 2010)

\begin{tabular}{lcccc}
\hline Demographic characteristics & $\begin{array}{l}\text { Positive } \\
\text { No (\%) }\end{array}$ & $\begin{array}{l}\text { Negative } \\
\text { No (\%) }\end{array}$ & Total (\%) & p value \\
\hline Age (years) & $11(0.9)$ & $127(10.1)$ & $138(11.0)$ & 0.45 \\
$15-19$ & $24(1.9)$ & $210(16.7)$ & $234(18.7)$ & \\
$20-24$ & $19(1.5)$ & $213(17.0)$ & $232(18.5)$ & \\
$25-29$ & $22(1.8)$ & $138(11.0)$ & $160(12.8)$ & \\
$30-34$ & $12(1.0)$ & $122(9.7)$ & $134(10.7)$ & \\
$35-40$ & $10(0.8)$ & $82(6.5)$ & $92(7.3)$ & \\
$41-45$ & $20(1.6)$ & $244(19.5)$ & $264(21.1)$ & \\
$>45$ & & & & \\
Gender & $38(3.0)$ & $583(46.5)$ & $621(49.5)$ & 0.001 \\
Male & $80(6.4)$ & $553(44.1$ & $633(50.5)$ & \\
Female & $118(9.4)$ & $1136(90.6)$ & $1254(100)$ & \\
Total & & & & \\
\hline
\end{tabular}

As shown in table 2, the risk of developing urinary tract infection among catheterized patients is about 2.6 times greater than those who did not have catheter insertion (OR: 18.9, 95\% CI., $\mathrm{p}=0.001)$. The risk of developing nosocomial UTI among patients who received prophylaxis was 1.2 times higher than those who did not receive prophylaxis (OR: 1.796, 95\% CI: $1.326-2.433, \mathrm{p}=0.001)$. Of the 87 patients who had underlying diseases, 16 (18.4\%) had confirmed UTI (OR: 4.3, 95\% CI: 2.731-6.690, $\mathrm{p}=0.002)$.

Table 2: History of catheterization and prophylaxis and culture status among UTI patients at Felege Hiwot Referral hospital (April to August, 2010)

\begin{tabular}{lcccccc}
\hline Category & Culture status & \multicolumn{2}{c}{ Total (\%) } & $\mathbf{X}^{\mathbf{2}}$ & \multicolumn{2}{c}{ Statistic } \\
\cline { 2 - 4 } & Positive (\%) & Negative (\%) & & & p-value & OR \\
\hline Catheterized & $85(38.5)$ & $136(61.5)$ & $221(100)$ & 265.9 & 0.001 & 18.9 \\
Non- Catheterized & $33(3.2)$ & $1001(96.8)$ & $1033(100)$ & & & \\
Prophylaxis used & $54(18.6)$ & $237(81.4)$ & $291(100)$ & 37.3 & 0.001 & 3.2 \\
Prophylaxis not used & $64(6.6)$ & $900(93.4)$ & $963(100)$ & & & \\
With underlying diseases & $16(18.4)$ & $71(81.6)$ & $87(100)$ & 8.85 & 0.02 & 4.3 \\
Without underlying diseases 102 (8.7) & $1065(91.3)$ & $1167(100)$ & & & \\
\hline
\end{tabular}


Gram negative bacteria accounted for $73(61.9 \%)$ of the bacteria isolated from the patients. E. coli and $S$. aureus were the most predominant pathogens isolated from urine samples, each with prevalence of $33(28.0 \%)$, followed by Klebsiella pneumonia,
Enterococcus spp. and Proteus mirabilis. Coagulate negative staphylococci (CNS), and Enterobacter spp. and other species constituted $10.2 \%$ of the isolates (table 3).

Table 3: Prevalence of bacteria among UTI patents with history of catheterization and prophylaxis use at Felege Hiwot Referral hospital (April to August, 2010) $n=118$

\begin{tabular}{|c|c|c|c|c|c|}
\hline \multirow[t]{2}{*}{ Bacterial Isolates } & \multirow{2}{*}{$\frac{\text { No. bacterial }}{\text { Isolates }(\%)}$} & \multicolumn{3}{|c|}{ Category } & \multirow[b]{2}{*}{$\begin{array}{l}\text { No prophylaxis } \\
\text { used (64) }\end{array}$} \\
\hline & & $\begin{array}{l}\text { Catheterized } \\
(85)\end{array}$ & $\begin{array}{l}\text { Non-catheterized } \\
\text { (33) }\end{array}$ & $\begin{array}{l}\text { Prophylaxis } \\
\text { used (54) }\end{array}$ & \\
\hline \multicolumn{6}{|l|}{ Gram- negative } \\
\hline E. coli & $33(28.0)$ & 28 & 5 & 16 & 17 \\
\hline K. pneumonia & $24(20.3)$ & 18 & 6 & 12 & 12 \\
\hline Proteus mirabilis & $7(5.9)$ & 6 & 1 & 1 & 6 \\
\hline Enterobacter spp. & $3(2.5)$ & 2 & 1 & 1 & 2 \\
\hline Proteus vulgaris & $2(1.7)$ & 0 & 2 & 1 & 1 \\
\hline P. aeruginosa & $2(1.7)$ & 2 & 0 & 0 & 2 \\
\hline S. marcescens & $2(1.7)$ & 2 & 0 & 0 & 2 \\
\hline \multicolumn{6}{|l|}{ Gram- positive } \\
\hline S. aureus & $33(28.0)$ & 23 & 10 & 17 & 16 \\
\hline Enterococcus spp. & $8(6.8)$ & 7 & 1 & 3 & 5 \\
\hline CNS & $3(2.5)$ & 0 & 3 & 2 & 1 \\
\hline Mixed Infection & $1(0.8)$ & 1 & 0 & 0 & 1 \\
\hline
\end{tabular}

$\overline{\mathrm{CNS}}=$ Coagulase negative staphylococci

Assessment of antimicrobial susceptibility patterns indicated that most isolates revealed a high rate of resistance $(>80 \%)$ to ampicillin, amoxycillin, chloramphenicol, cloxacillin and amoxycillin/ clavulanic acid. Gram positive bacterial isolates showed high a level of resistance to ampicillin, cloxacillin (92.4), chloramphenicol, and amoxycillin (84.8 - 97.4\%) (Data not shown). Gram negative bacteria were highly resistant to ampicillin and amoxycillin (90.9 - 99.2\%). E. coli showed high level of resistance against ampicillin, 49 (100\%), amoxycillin, 42 (85.7), chloramphenicol, 41 (83.7\%), and tetracycline 40 (81.6\%).

\section{Discussion}

Urinary tract infections are one of the most common hospital-acquired infections diagnosed worldwide. Availability of new antimicrobials has improved the management of UTIs. However, the management of UTI infections has been jeopardized by increase in emergence of antimicrobial drug resistance.

A statistically significant difference was observed between genders as majority of the pathogens were isolated from females $(p<0.001)$. Studies conducted all over the world have reported differences in the prevalence between females and males ${ }^{9,17}$. Physiological and anatomical differences have accounted for the differences in males and females. This is because compared to females the drier environment in the urethra prevents the optimal growth of bacteria. The antimicrobial activity of prostate secretions and longer distance between the anus and urethra meatus in males are among the factors responsible for the differences in prevalence of pathogens between the two genders ${ }^{18}$.

In this study, the presence of underlying diseases and catheterization were the risk factors for odds of developing nosocomial UTI which was reported previously ${ }^{19,20}$. In this study the association between antibiotic prophylaxis and occurrence of nosocomial UTI agreed with other reports ${ }^{21}$.

$E$. coli and $S$. aureus were the most predominant bacteria isolated from nosocomial urinary tract infections. The isolation rates of E. coli and other pathogens in this study were comparable to the rates documented previously ${ }^{9,11}$. However, the rates were generally lower than those from other reports ${ }^{17,22}$ and higher than the results of other studies ${ }^{10}$. Gram negative bacteria were more responsible for UTI than gram positive bacteria and this finding is in agreement with the findings of previous studies ${ }^{5,10}$. Differences in identification methods are known to influence the relative 
prevalence of bacteria which makes comparison difficult ${ }^{12}$. Bacterial etiologies of UTI can show geographic variations and may even vary over time within a population ${ }^{9,23}$. This result concurred with the results of studies conducted in Ethiopia and other countries ${ }^{9,24}$.

The frequency of bacterial etiologies of this study differ from the other reports in which the most frequently isolated causative agents in catheter infections were Pseudomonas spp. (17\%), Klebsiella spp. (16\%), E. coli (13\%), Acinetobacter spp. (12\%), Coagulase negative staphylococci $(11 \%)$ and methicillin-resistant $S$. aureus (MRSA) $(9 \%)^{25}$. The results of this study are similar to the results of a study conducted in Taipei, Taiwan ${ }^{19}$. Clinically significant bacterial isolates such as E. coli, S. aureus and $K$. pneumonia were common in catheterized patients. Similar results have been reported from previous studies ${ }^{11}$. Catheters support the colonization of biofilm infection where the pathogens adhere to urinary tract, to the foreign material or necrotic tissue and are embedded in exopolysacharide matrix ${ }^{26}$.

The antibiotic resistance patterns reported in this study for ampcillin, chloramphenicol, gentamicin, and trimethoprim-sulphomethoxazol were higher than previous reports done in Ethiopia ${ }^{27,28}$. Overall, statistically significant resistance rates were demonstrated to amoxycillin, erythromycin and tetracycline $(\mathrm{p}<0.001)$. These rates are higher than those reported from Ethiopia ${ }^{10}$ and other countries ${ }^{22,28}$. Increasing drug resistance to these and other antimicrobials has been documented from previous studies ${ }^{22}$. Ciprofloxacin was effective against most bacterial isolates. High rates of sensitivity to ciprofloxacin have been documented from earlier studies ${ }^{17,29}$.

In this study, the gram negative enteric bacilli were highly resistant to beta lactam antibiotics ampicillin and amoxycillin. Staphylococci in this study showed $76.9 \%$ resistance to tetracycline, $74.8 \%$ resistance to cotrimoxazole and $74.8 \%$ resistance to gentamicin where as in other reports resistance of $100 \%$ to tetracycline, $80 \%$ to cotrimoxazole and $60 \%$ to gentamicin ${ }^{30}$ were shown.

\section{Limitation of the study}

This study did not consider etiology of UTIs other than bacteria and anaerobic bacteria due to lack of facility.

\section{Conclusion}

This study shows high incidence of nosocomial urinary tract infection in the hospital. The most predominant bacteria isolated were gram negative bacteria. Catheterization and preoperative antibiotic prophylaxis were found to be the risk factors for nosocomial infection. Most bacteria were resistant to cloxacillin and amoxycillin clavulanic acid. Ciprofloxacin is considered as appropriate antimicrobial for empirical treatment of UTI in the area. Effective infection prevention measures should be in place to reduce the prevalence of nosocomial UTIs.

\section{Acknowledgements}

The authors would like to thank head nurses of Surgical, Gynecology and Obstetrics wards for specimen collection and completing the questionnaire. We also thank Mr Atnaf Alem for provision of laboratory facilities. The financial support made from the Addis Ababa University School of Graduate Studies is duly acknowledged.

\section{References}

1. Toni RL, Culvert LL. Safer Hospital Stay and Reducing Hospital-Born Infections. Health Scout News. http://www.healthscout.com, 2003 (accessed January 9, 2010).

2. Nguyen V. Hospital-acquired infections. eMedicine. http://www.emedicine.com 2004 (accessed January 13, 2010).

3. Ducel G , Fabry J , Nicolle L (eds). Prevention of Hospital-acquired Infections, A Practical Guide, 2nd ed., WHO/CDS/CSR/EPH/ 2002.12. WHO, 2002: Geneva.

4. Rahman MH, Anson J. Pre operative anti-bacterial prophylaxis. Pharm J. 2004; $272: 743-45$.

5. Tice AD. Short course therapy of acute cystitis: a brief review of therapeutic strategies. J Antimicrob Chemother. 1999; 43: 85-93.

6. Foxman B, Brenda G, James K. et al. Risk factors for second urinary tract infection among College Women. Am J Epidemiol. 2000; 151: 119405.

7. Tessema B, Kassu A, Mulu A, Yismaw G. Predominant isolates of urinary tract pathogens and their antimicrobial susceptibility patterns in Gondar University Teaching Hospital, northwest Ethiopia. Ethiop Med J. 2007; 1:61-7.

8. Biadglegn F, Abera B. Antimicrobial resistance patterns of bacterial isolates from urinary tract 
infections at Felege Hiwot Hospital, Ethiopia. Ethiop J Health Dev. 2009; 23: 236-38.

9. Grude N, Tveten Y, Kristiansen BE. Urinary tract infections in Norway: bacterial etiology and susceptibility. A retrospective study of clinical isolates. Clin Microbiol Infect. 2001; 7: 543-47.

10. Moges F, Genetu A, Mengistu G. Antibiotic sensitivity of Bacterial pathogens in Urinary tract infections at Gondar Hospital, Ethiopia. East Afr Med J . 2002; 79:140-42.

11. De Francesco MA, Giuseppe R, Laura P, Riccardo N, Nino M. Urinary tract infections in Brescia, Italy: Etiology of uropathogens and antimicrobial resistance of common Uropathogens. Med Sci Monit. 2007; 13: 13644.

12. Leegaard TM, Caugant DA, Froholm LO, Hoiby EA. Apparent difference in antimiovrobial susceptibility as a consequence of national guidelines. Clin Microbiol Infec. 2000; 6:290.

13. Horan TC, Gaynes RP. Surveillance of nosocomial infections. In: Hospital Epidemiology and Infection Control, 3rd ed., Mayhall CG, editor. Philadelphia:Lippincott Williams \& Wilkin. 2004; 1659-1702.

14. Cheesbrough M. Medical laboratory manual for tropical countries. 2nd edition: England: Butterworth-Heineman LTD, 1991; 114-6.

15. Bauer AW, Kirby WMM, Sherris JC, Turck M. Antibiotic susceptibility testing by a standardized single disk method. Am J Clin Pathol. 1966; 36: 493-96.

16. Clinical and Laboratory Standards Institute. Performance Standards for Antimicrobial Susceptibility Testing; Seventeenth Information Supplement. CLSI document M100-S17, Clinical and Laboratory Standards Institute Wayne Pennsylvania, 2006. 4

17. Kiffer CR, Caio M, Carmen PO, Jorge LS. Antibiotic Resistance and Trend of Urinary Pathogens in General Outpatients from a Major Urban City. International Braz. J Urol. 2007; 33: 42-49.

18. Hooton TM. Pathogenesis of urinary tract infections: an update. J Antimicrob Chemother. 2000; 46: S1: 1-17.

19. Adukauskiene D, Cicinskaite I, Vitkauskiene A, Macas A, Tamosiûnas R, Kinderyte A Hospital-acquired urinary tract infections. Medicina (Kaunas) 2006; 42: 957-64.
20. Hossam M, Ashour, El-Sharif A. Species distribution and antimicrobial susceptibility of gram-negative aerobic bacteria in hospitalized cancer patients. J Transl Med 2009; 7: 14 10.1186/1479-5876-7-14..

21. Ganguly PS, Khan Y, Malik A. Nosocomial infection and hospital procedures. Indian J Comm Med. 2000; 25: 39-45.

22. Min-Hua T, Wen-Tsung L, Wei-Jen L. ChingShen T, Mong-Ling C, Chih-Chien W. Changing trend in antimicrobial resistance of pediatric uropathogens in Taiwan Pediatr Int. 2008; 50:797-800.

23. Barre, SP, MA, Savage MP, Rebec AB, Guyoy NA, Shrimpton SB. Antibiotic Sensitivity of bacteria associated with community-acquired urinary tract infection in Britain. J Antimicrob Chemother. 1999; 44: 359-65.

24. El-Mahmood AM, Atimi AT, Tirmidhi B. Mohammed A. Antimicrobial susceptibility of some quinolone antibiotics against some urinary tract pathogens in a tertiary hospital, Yola, Adamawa State, Nigeria. J Clin Med Res. 2009; 1: 26-34.

25. Cetin BD, Hasman H, Ozcan N, Gündüz A, Harmankaya O, Seber E. Epidemiology and etiology of catheter-related nosocomial infections in a Turkish hospital. Infez.Med. 2005; 13:152-9

26. Reid G. Biofilms in infectious diseases and on medical devises. Int J Antimicrobial Agents. 2003; 22:223-26.

27. Gedebou M, Habte-Gabr E, Kronvall G, Yoseph S. Hospital-acquired infections among obstetric and gynecological patients at Tikur Anbessa Hospital, Addis Ababa. J Hosp Infect. 1988; 11:50-59.

28. Habte-Gabr E, Gedebou M, Kronvall G. Hospital-acquired infections among surgical patients in Tikur Anbessa Hospital, Addis Ababa, Ethiopia. Am J Infect Control.1988; 16:713.

29. Kahlmeter G. An international survey of the antimicrobial susceptibility of pathogens from uncomplicated urinary tract infections: the ECOSENS Project. I Antimicrobl Chemother. 2003; 51: 69-76.

30. Singh AK, Sen MR, Anupurba SB, Hattacharya P. Antibiotic sensitivity pattern of the bacteria isolated from nosocomial infections in ICU. J. Comm Dis. 2002; 34:257-63. 